\title{
Establishing a blueprint for successful liver transplantation for alcohol-related cirrhosis: the importance of a multidisciplinary team
}

\author{
José Ursic-Bedoya ${ }^{1}$, Hélène Donnadieu-Rigole ${ }^{2}$ \\ ${ }^{1}$ Department of Hepatogastroenterology, Hepatology and Liver Transplantation Unit, Saint Eloi Hospital, University of Montpellier, Montpellier, \\ France; ${ }^{2}$ Department of Addictology, Saint Eloi Hospital, University of Montpellier, Montpellier, France \\ Correspondence to: Dr. José Ursic-Bedoya, MD, PhD. St-Eloi University Hospital, Department of Hepatogastroenterology, Hepatology and Liver \\ Transplantation Unit, 80 Avenue Augustin Fliche, 34295 Montpellier, France. Email: jose.ursicbedoya@chu-montpellier.fr. \\ Comment on: Carrique L, Quance J, Tan A, et al. Results of early transplantation for alcohol-related cirrhosis: integrated addiction treatment with low \\ rate of relapse. Gastroenterology 2021;161:1896-1906.e2.
}

Submitted Dec 17, 2021. Accepted for publication Dec 28, 2021.

doi: 10.21037/hbsn-21-532

View this article at: https://dx.doi.org/10.21037/hbsn-21-532

Liver transplantation (LT) for alcohol-related liver disease (ALD) has come a long way since the implementation of LT as a standard procedure. Initially considered a contraindication due to poor outcomes and moral issues $(1,2)$, it is nowadays the most common indication for LT in Western countries $(3,4)$. Patient and graft survival in this setting are excellent (5). However, relapse rates remain high (6), which jeopardizes long-term survival and the acceptance of the transplant team for these procedures. The evaluation of the suitability to a LT for a potential candidate is therefore essential. The length of sobriety, namely over six months, has longtime been considered as the condition sine qua non. The "6-month rule" is insufficient to predict the risk of relapse and is progressively being abandoned by learned societies recommendations $(7,8)$. Moreover, situations in which a recent alcohol consumption is obvious, such as alcoholic hepatitis or positive blood and/or urine test before the procedure, are associated with good outcomes (9-11).

The utilization of criteria based solely on the length of sobriety is not equitable since it excludes some patients at low risk of relapse. Besides, the benefit of an "early" versus "delayed" LT strategy has been demonstrated by many teams $(12,13)$. Instead of concentrating only on the length of sobriety, the focus must be done in the pretransplant evaluation and the post-transplant support. Easy-to-use clinical scores such as High Risk Alcoholism Relapse (HRAR, which includes daily alcohol consumption, length of drinking history, and previous treatment history) are reliable tools to predict patients at risk of relapse (14). Furthermore, systematic referral to an addiction specialist improves the quality of the pre-transplant evaluation and decreases post-transplant relapse rates $(15,16)$. When patients are evaluated by an addiction specialist after the LT, a relapse is more frequently detected, which can be helpful for the graft and patient survival (17).

Yet, few transplant teams seem ready to implement a multidisciplinary strategy to improve patient selection and post-transplant outcomes. In a future issue of Gastroenterology, Carrique et al. (18) provide a blueprint for the implementation of a successful program aiming to improve LT for ALD results while enabling an equitable and multidisciplinary assessment of potential candidates as well as a structured support to prevent (and early detect) relapse. The "Ontario ALD Pilot Program" was launched in 2018 in response to an increasing rate of patients referred for pre-transplant evaluation for ALD. It consists in a finely tuned network of transplant hepatologists, addiction and consultation-liaison psychiatrists, social workers, and a nurse practitioner. The main originality of this program is the lack of an abstinence requirement to proceed to the evaluation, even in the absence of alcoholic hepatitis. All patients meeting criteria for alcohol use disorder (AUD) were required to participate in relapse prevention therapy (RPT), consisting in individual sessions following a manual tailored for this program. An impressive 703 patients were referred in a 29 -month period, while only $14 \%$ 
(101 patients) were deemed suitable for listing and 6.3\% (44 patients) were ultimately transplanted. Short-term survival was satisfactory, like the one obtained with a historic control-group of patients with a length of abstinence $>6$-month. Only 3 patients (6.8\%) experienced relapse post-LT. Interestingly, in an analysis of relapse risk-factors including patients evaluated (receiving or not a transplant), age and Model for End-stage Liver Disease (MELD) score at listing were protective factors, while severe AUD or marital status where not statistically associated with relapse.

The findings of this work must be tempered by the very short follow-up length for ALD pilot patients, which certainly underestimates the true relapse rates. It is also a single-center experience, difficult to replicate since a significant amount of resources and institutional willingness are needed.

This outstanding study highlights the fact that the burden of relapse risk should not be borne exclusively by the patient; the transplant team has a major responsibility to prevent this risk by providing a risk reduction program. Several questions are also raised by this experience. First, since alcohol consumption in Western countries is so prevalent, should this kind of follow-up and pre-transplant evaluation be offered to all LT candidates, regardless of the etiology of the liver disease? Then, is there enough evidence to set up integrative management pre- and post-transplant as standard of care? A comparison with a longer follow-up focusing in graft and patient survival as well as overall and harmful relapse should answer this question. Finally, if the evidence becomes indisputable, are the transplant teams ready to implement such a heavy organization to ensure acceptable results?

\section{Acknowledgments}

Funding: None.

\section{Footnote}

Provenance and Peer Review: This article was commissioned by the editorial office, Hepatobiliary Surgery and Nutrition. The article did not undergo external peer review.

Conflicts of Interest: Both authors have completed the ICMJE uniform disclosure form (available at https://hbsn. amegroups.com/article/view/10.21037/hbsn-21-532/coif). The authors have no conflicts of interest to declare.
Ethical Statement: The authors are accountable for all aspects of the work in ensuring that questions related to the accuracy or integrity of any part of the work are appropriately investigated and resolved.

Open Access Statement: This is an Open Access article distributed in accordance with the Creative Commons Attribution-NonCommercial-NoDerivs 4.0 International License (CC BY-NC-ND 4.0), which permits the noncommercial replication and distribution of the article with the strict proviso that no changes or edits are made and the original work is properly cited (including links to both the formal publication through the relevant DOI and the license). See: https://creativecommons.org/licenses/by-nc-nd/4.0/.

\section{References}

1. Starzl TE, Putnam CW, Ishikawa M, et al. Current policies in hepatic transplantation: candidacy of patients with alcoholic liver disease or preformed antidonor antibodies and a reappraisal of biliary duct reconstruction. Ann N Y Acad Sci 1975;252:145-58.

2. Atterbury CE. The alcoholic in the lifeboat. Should drinkers be candidates for liver transplantation? J Clin Gastroenterol 1986;8:1-4.

3. Cholankeril G, Gadiparthi C, Yoo ER, et al. Temporal trends associated with the rise in alcoholic liver diseaserelated liver transplantation in the United States. Transplantation 2019;103:131-9.

4. Belli LS, Perricone G, Adam R, et al. Impact of DAAs on liver transplantation: major effects on the evolution of indications and results. An ELITA study based on the ELTR registry. J Hepatol 2018;69:810-7.

5. Burra P, Senzolo M, Adam R, et al. Liver transplantation for alcoholic liver disease in Europe: a study from the ELTR (European Liver Transplant Registry). Am J Transplant 2010;10:138-48.

6. Kodali S, Kaif M, Tariq R, et al. Alcohol relapse after liver transplantation for alcoholic cirrhosis-impact on liver graft and patient survival: a meta-analysis. Alcohol Alcohol 2018;53:166-72.

7. Crabb DW, Im GY, Szabo G, et al. Diagnosis and treatment of alcohol-associated liver diseases: 2019 Practice Guidance from the American Association for the study of liver diseases. Hepatology 2020;71:306-33.

8. European Association for the Study of the Liver. EASL Clinical Practice Guidelines: Management of alcohol- 
related liver disease. J Hepatol 2018;69:154-81.

9. Ursic-Bedoya J, Dumortier J, Altwegg R, et al. Alcohol consumption the day of liver transplantation for alcoholassociated liver disease does not affect long-term survival: a case-control study. Liver Transpl 2021;27:34-42.

10. Mathurin P, Moreno C, Samuel D, et al. Early liver transplantation for severe alcoholic hepatitis. N Engl J Med 2011;365:1790-800.

11. Lee BP, Mehta N, Platt L, et al. Outcomes of early liver transplantation for patients with severe alcoholic hepatitis. Gastroenterology 2018;155:422-430.e1.

12. Herrick-Reynolds KM, Punchhi G, Greenberg RS, et al. Evaluation of early vs standard liver transplant for alcoholassociated liver disease. JAMA Surg 2021;156:1026-34.

13. Lee BP, Samur S, Dalgic OO, et al. Model to calculate harms and benefits of early vs delayed liver transplantation for patients with alcohol-associated hepatitis. Gastroenterology 2019;157:472-480.e5.

14. De Gottardi A, Spahr L, Gelez P, et al. A simple score

Cite this article as: Ursic-Bedoya J, DonnadieuRigole H. Establishing a blueprint for successful liver transplantation for alcohol-related cirrhosis: the importance of a multidisciplinary team. HepatoBiliary Surg Nutr 2022;11(1):150-152. doi: 10.21037/hbsn-21-532 for predicting alcohol relapse after liver transplantation: results from 387 patients over 15 years. Arch Intern Med 2007;167:1183-8.

15. Addolorato G, Mirijello A, Leggio L, et al. Liver transplantation in alcoholic patients: impact of an alcohol addiction unit within a liver transplant center. Alcohol Clin Exp Res 2013;37:1601-8.

16. Donnadieu-Rigole H, Jaubert L, Ursic-Bedoya J, et al. Integration of an addiction team in a liver transplantation center. Liver Transpl 2019;25:1611-9.

17. Donnadieu-Rigole H, Olive L, Nalpas B, et al. Followup of alcohol consumption after liver transplantation: interest of an addiction team? Alcohol Clin Exp Res 2017;41:165-70.

18. Carrique L, Quance J, Tan A, et al. Results of early transplantation for alcohol-related cirrhosis: integrated addiction treatment with low rate of relapse. Gastroenterology 2021;161:1896-1906.e2. 